\title{
Recognition of International Education in Japanese Teachers
}

\author{
Masami Yoshida ${ }^{1}$ \\ ${ }^{1}$ Faculty of Education, Chiba University, Japan \\ Correspondence: Masami Yoshida, Faculty of Education, Chiba University, 1-33 Yayoi Inage 263-8522, Japan.
}

Received: November 28, 2016

Accepted: December 25, 2016 Online Published: December 26, 2016

doi:10.11114/jets.v5i2.2016

URL: http://dx.doi.org/10.11114/jets.v5i2.2016

\begin{abstract}
Education for international understanding in Japan was focused to develop its own national identity as well as to recognize its coexistence through intercultural education. Then, we have investigated the opinions of Japanese school teachers in terms of their recognition of the necessary content to introduce school instruction of intercultural education using a questionnaire method. In the questionnaire, 14 items of three principles were extracted from the criteria of UNESCO (United Nations Educational, Scientific, and Cultural Organization). For analyzing the collected data, the geometric mean was used. Subsequently, a one-way ANOVA test and multiple-comparison procedures were conducted. By including teachers in suburban areas in Japan, we obtained 123 valid responses. All items showed a necessary level of geometric means, and particularly items of the first principle "respect cultural identity" and items of the second principle "provide knowledge for participation" showed statistically significant positive necessity levels. However, an answer of "I have never thought" increased in the third principle "provide a chance to contribute" that was closely related to present world concern of global citizenship education and statistically was not significant. From the result of the multiple-comparison procedures of the second principle and the third principle, seven pairs of statistically different items were extracted. Then, we discussed the enhancement between Japan and UNESCO and influence of school environment in Japan.
\end{abstract}

Keywords: intercultural education, in-service teacher, education for international understanding, global citizenship education, UNESCO

\section{Introduction}

The initiation of international education in Japan was affected by a discussion of the United Nations Educational, Scientific and Cultural Organization (hereinafter UNESCO).

A term "education for international understanding" was first-time introduced in 1947 (UNESCO, 1947), and the subsuming area was expanded in the recommendation report to "education for international understanding and co-operation" in 1954 (UNESCO, 1954).

Afterwards, importance of international education was highlighted in 1974 during the general conference (UNESCO, 1974). In the expert meeting, the area of the international education was elaborated, and UNESCO emphasized actions of people in the world by combining keywords of international understanding, co-operation, and peace.

The terms 'international understanding', 'co-operation' and 'peace' are to, be considered as an indivisible whole based on the principle of friendly relations between peoples and States having different social and political systems and on the respect for human rights and fundamental freedoms. In the text of this recommendation, the different connotations of these terms are sometimes gathered together in a concise expression, 'international education'.

(UNESCO, 1974)

Subsequently, Ministry of Education, Culture, Sports, Science and Technology in Japan (hereinafter MEXT) released a report, and this report included one emphasis of international understanding (MEXT, 1988). According to this report, the importance of developing an in-depth understanding of world history and culture as well as culture and the tradition of Japan was promoted to develop the necessary ability to live in an international arena. In other words, education for international understanding in Japan was focused to develop its own national identity as well as to recognize its coexistence through intercultural education (Nakanishi, 1993). 
Successively, MEXT released guidelines of lesson content for the international understanding in a report: "the way of the education of our country which anticipated the 21st century" (MEXT, 1996). The following three elements are described as the normative foundation of education for international understanding:

1) To promote the capacity and competence to have a wide vision, intercultural understanding, and to respect others and to live with different cultures people.

2) To establish the Japanese character and individual personality for international understanding.

3) To foster the fundamental ability for self-assertion and to show intention by respecting the views of others in the international society, and to develop communication competence of fundamental and expressiveness of foreign languages.

As such, intercultural education exemplified one of three elements shown in 1).

To promote diversity, education for international studies cover many fields, including human rights education, environmental education, development education, peace education, global citizenship education (hereinafter GCE), and intercultural education (National Institute for Educational Policy Research, 2014). Also, all fields are directed to global coexistence (Ootsu, 1997). Particularly, GCE has been integrated into transformative learning, where it empowers students to transform themselves into multicultural society with a constructive manner (UNESCO, 2015a). Similarly, GCE was recognized in Japan to contain intercultural education, co-operation education, environmental education, human rights education, and peace education (Ootsu, 1994). Then, intercultural education was recognized as an important factor both for international understanding and GCE.

At that time, Tada (1997) also asserted that future educational challenges in Japanese school education would involve how to develop GCE, and the most direct and effective chance was to execute GCE in education for international understanding.

Also, MEXT shows the following conceptual target for next international education.

"Developing universal capacity and competence as a human that can show own personality equal to the occasion."

(Cited from MEXT, 2016).

Summarizing the situation of education for international understanding in Japan, many fields were merged, but they all can be classified into two major views. One was education from the perspective of local view (based on the viewpoint of daily school life), and another was a global educational view (based on global point of view). Also, there were strong differences in origin, principle, objectives, and direction of target between both views. Teachers were confused on how to focus their lessons (Sato, 2007).

Particularly, the view from local cases in which activities stemming from educational policy were deployed such as international exchange programs, foreign language training and cares for students from foreign countries brought conceptual difficulties for teachers to understand GCE. In addition, it could be summarized differences of intercultural education between UNESCO and schools in Japan (shown in Table1).

Table 1. Comparison of viewpoints of intercultural education between UNESCO and schools in Japan

\begin{tabular}{|c|c|c|}
\hline Viewpoints & UNESCO & Schools in Japan \\
\hline $\begin{array}{l}\text { A strength of intercultural } \\
\text { education }\end{array}$ & $\begin{array}{l}\text { Mixed with multiculturalism } \\
\text { interculturalism }\end{array}$ & More interculturalism \\
\hline Classroom & Majority and minority groups & $\begin{array}{l}\text { Few or no students from foreign } \\
\text { countries }\end{array}$ \\
\hline Local and global & Interrelated & Somehow being separated \\
\hline Target & Strength of equality and human rights & Peaceful coexistence \\
\hline $\begin{array}{l}\text { Immediate necessity of } \\
\text { challenge }\end{array}$ & Universalism and cultural pluralism & Universalism \\
\hline Emerging learning & $\begin{array}{l}\text { Global citizenship, human rights education, } \\
\text { peace education, education for sustainable } \\
\text { development }\end{array}$ & International communication \\
\hline Curriculum activities & Inclusive curriculum & Curriculum expansion \\
\hline School expansion & $\begin{array}{l}\text { Community enhancement, lifelong } \\
\text { education }\end{array}$ & $\begin{array}{l}\text { Student exchange, international } \\
\text { cultural exchange }\end{array}$ \\
\hline
\end{tabular}

On present dissemination of education for international understanding, the reported implementation rate is rather inactive; it is $62.6 \%$ in elementary schools (grade 1-6) and 25.3\% in lower-secondary schools (grade 7-9) (MEXT, 2016).

Even from the data, which is relevant to the local perspective, the number of students from foreign countries who need 
the support of the Japanese language are 27,198 (0.20\% in total students) and who have foreign nationalities are 73,289 (0.54\% in total students) (MEXT, 2014). Diversity and minorities background students are fewer in the classroom.

However, chances to feel the importance of intercultural education in students' daily lives and community have been increased. Alien residents are increasing, and now we have 2.2 million foreigners living in Japan (Ministry of Justice, 2016).

Generally, intercultural education is affected by the situation of the country. For example, US focused on critical multiculturalism, UK focused on anti-racist education, and Germany focused on critical intercultural pedagogy (Ermenc, 2015). However, these characteristics were drawn by ideas from their culturally diverse society, which have more minority groups than in Japan.

For that reason, concrete data should be collected to understand the gap between the reality of teachers' opinions and the world trend to discuss the future for intercultural education in Japan.

On this account, the purpose of this study is to investigate the opinions of Japanese in-service teachers in terms of their recognition of the necessity of intercultural education. We adopted a questionnaire method, and the items were developed referring to the UNESCO criteria.

\section{Methodology}

Until now, the concept of directivity to promote international education has been developed in UNESCO, and methods of intercultural education are written in a report: "UNESCO guidelines on intercultural education" (UNESCO, 2006). In this report, intercultural education aims to go beyond passive coexistence to achieve a sustainable way of living together in multicultural societies through the creation of understanding, respect, and dialogue between different cultural groups.

Three stages of principles and relevant necessities of curricula and lesson materials, teaching method, teacher training, and communication were noted in the report. In this study, the following items were extracted and arranged as questionnaire items.

\subsection{Questionnaire Items}

The following 14 items were arranged in the questionnaire.

\subsubsection{Principle 1: Respect Cultural Identity}

Intercultural education respects the cultural identity of the learner through the provision of culturally appropriate and responsive quality education for all.

For this intercultural education, appropriate teacher ability should involve:

P1-1. A teacher familiarizes with the cultural heritage of minority groups.

P1-2. A teacher familiarizes with practical, participatory, and contextualized teaching methods in an intercultural classroom.

P1-3. A teacher raises awareness of the educational and cultural needs of minority groups.

P1-4. A teacher imparts the ability to adapt educational contents, methods, and materials according to the needs of groups whose cultures diverge from the majority group.

P1-5. A teacher facilitates the application of diversity as a tool in the classroom to benefit students.

\subsubsection{Principle 2: Provide Knowledge for Participation}

Intercultural education provides every learner with the cultural knowledge, attitudes, and skills necessary to achieve active and full participation in society.

To enable students to participate, the lesson content should involve:

P2-1. A teacher imparts knowledge about the history, traditions, language, and culture of existing minorities to majority groups.

P2-2. A teacher imparts knowledge about Japanese society as a whole to minorities.

P2-3. A teacher aims at eliminating prejudices about culturally distinct population groups within Japan.

P2-4. A teacher involves various cultural systems through the presentation of knowledge from different cultural perspectives.

P2-5. A teacher creates a comprehensive knowledge of reading, writing and the spoken word, enabling the citizen to gain access to information, to understand clearly the situation in which he or she is living, to express his or her needs, and to take part in activities in the social environment. 


\subsubsection{Principle 3: Provide a Chance to Contribute}

Intercultural education provides all learners with cultural knowledge, attitudes, and skills that enable them to contribute to respect, understanding, and solidarity among individuals, ethnic, social, cultural, and religious groups and nations.

To develop skills for contribution, the school should provide:

P3-1. Direct contacts and regular exchanges between pupils, students, teachers and other educators in different countries or cultural environment.

P3-2. The implementation of joint projects between establishment and schools from different countries, with a view of solving common problems.

P3-3. The setting up of international networks of pupils, students, and researchers working towards the same objectives.

P3-4. The acquisition of abilities for conflict resolution and mediation.

\subsection{Scale}

We construct a questionnaire on nine-point scales. And, we added one selection of "I have never thought (hereinafter "never thought")" considering the survey result shown in section 1 of rather inactive implementation of education for international understanding in Japan.

Teachers' responses were collected by using the scale shown in Table 2.

Table 2. Intensity of importance

\begin{tabular}{cc}
\hline $\begin{array}{c}\text { Intensity of } \\
\text { importance }\end{array}$ & Definition \\
\hline N/A & I have never thought \\
$1 / 9$ & Absolutely unnecessary \\
$1 / 7$ & Very much unnecessary \\
$1 / 5$ & Much necessary \\
$1 / 3$ & Somewhat unnecessary \\
1 & Neutral \\
3 & Somewhat necessary \\
5 & Much necessary \\
7 & Very much necessary \\
9 & Absolutely necessary \\
\hline
\end{tabular}

The scaling and intensity of questionnaire used were proposed by Saaty (1989), and geometric mean was used to calculate scores.

\subsection{Implementation}

A total of 123 valid responses were collected during 4-5 August 2016 in the in-service teachers' training seminars that were held in a suburban area of Chiba prefecture in Japan. All of them have more than 10 years teaching experience and work at schools in suburban areas. 77 teachers work in primary schools, and 46 teachers work in lower-secondary schools in Chiba Prefecture, Japan.

\section{Results}

\subsection{Principle 1}

This principle involves items regarding respecting cultural identity. All items have not been required in their routine teaching work, but these items are becoming important in their work of school and classroom management. In principle 1 , a mean of "never thought" was $14.3 \%$ in all answers. Then, over $85 \%$ of teachers felt it a necessity.

Table 3. Recognition of necessity about Principle 1

\begin{tabular}{cc}
\hline Item No. & $\begin{array}{l}\text { Geometric mean } \\
\text { (Geometric standard deviation) }\end{array}$ \\
\hline P1-1 & $4.51(1.83)^{*}$ \\
P1-2 & $3.95(1.95)^{*}$ \\
P1-3 & $4.60(1.84)^{*}$ \\
P1-4 & $4.39(1.98)^{*}$ \\
P1-5 & $4.64(1.87)^{*}$ \\
\hline & ${ }^{*} \mathrm{P}<0.05$
\end{tabular}

Table 3 shows the geometric means of items in terms of teaching students to give respect to the cultural identity through 
the provision of culturally appropriate education. In other words, this principle concerns preparation of teachers to impart important knowledge to students.

A geometric mean of 1.0 shows a neutral intensity between "necessary" and "unnecessary". Also, an asterisk shows the determination of an opinion is a necessary level with a significance level of $5 \%$.

The geometric means of all five items were identified to be higher than 1.0 and determined positively the "necessary" level of opinions. This result is depicted as a radar chart in Figure 1. The colored inner area with a value less than 1.0 represents the area of the "unnecessary".

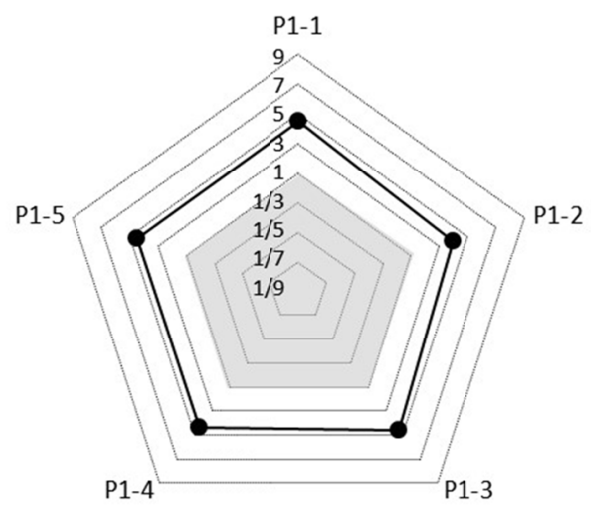

Figure 1. Result of Principle 1

About knowledge provision to students, teachers highly accepted targets of both the majority group (P1-3) and the minority group (P1-4). Also, anti-prejudice was held in esteem, and it could be concluded that omnipresent truth of equality and human rights was highly recognized, and their cultural standard was high and at least they had no potential barrier to discussing diversity. About P1-2, the geometric mean was a lower value, because teachers needed to prepare not only knowledge, but also instructional skills. However, this geometric mean still illustrated a positive significance of necessity. In addition, P1-5 showed a higher geometric mean to introduce information of diversity into lesson content.

The log-transformed data were processed using list-wise case deletion and introduced into further analysis. There is no significant difference between the items of principle 1, as determined by a one-way analysis of variance (hereinafter ANOVA) $(\mathrm{F}[4,470]=0.79 ; \mathrm{P}>0.05)$.

\subsection{Principle 2}

This principle involves items regarding provision of knowledge for participation. In this principle, the mean of the response "never thought" was $16.1 \%$ in all answers of respondents. Then, over $80 \%$ of teachers felt it was a necessity.

Table 4 shows the geometric means of items in terms of provision of knowledge, attitude, and skills for students' participation in society. Then, this principle advanced teachers' recognition to develop students' ability.

Table 4. Recognition of necessity about Principle 2

\begin{tabular}{cc}
\hline $\begin{array}{c}\text { Item } \\
\text { No. }\end{array}$ & $\begin{array}{c}\text { Geometric mean } \\
\text { (Geometric standard deviation) }\end{array}$ \\
\hline P2-1 & $4.49(1.77)^{*}$ \\
P2-2 & $5.04(1.85)^{*}$ \\
P2-3 & $5.75(1.76)^{*}$ \\
P2-4 & $4.25(1.93)^{*}$ \\
P2-5 & $3.03(2.57)$ \\
\hline
\end{tabular}

The geometric means of four out of five items were identified as a statistically significant "necessary" level.

This result is depicted as a radar chart in Figure 2. 


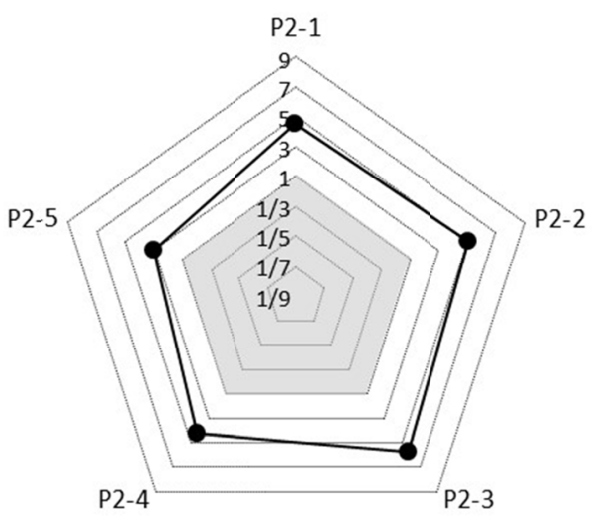

Figure 2. Result of Principle 2

P2-2 and P2-3 relate to cares of classroom management for minorities. In addition, P2-2 and P2-3 showed higher geometric means in all items of this questionnaire. This is because these items relate explicitly to indispensable cares when they have a student of a minority group. The number of minority students are increasing in Japan but many of teachers have limited experience, and that's why a classroom teacher felt the need to prepare specific cares when they encounter minorities. These are becoming important in their work. P2-1 and P2-4 are intended to develop new lesson content that target majority groups. On the other hand, P2-5 includes diversification of the lesson environment.

Continuously, a significant difference was identified for items in principle 2, as determined by a one-way ANOVA $(\mathrm{F}[4,425]=10.5 ; \mathrm{P}<0.01)$.

Subsequently, the multiple-comparison procedure (post-hoc test) using the Steel-Dwass test was conducted (see Table 5).

Table 5. Result of Steel-Dwass test of principle 2 items

\begin{tabular}{rllll}
\hline $\mathrm{i} \backslash \mathrm{j}$ & $\mathrm{P} 2-2$ & $\mathrm{P} 2-3$ & $\mathrm{P} 2-4$ & $\mathrm{P} 2-5$ \\
\hline $\mathrm{P} 2-1$ & 3.33 & $6.21^{* *}$ & 0.167 & $4.31^{*}$ \\
$\mathrm{P} 2-2$ & & 3.24 & 3.42 & $6.80^{* *}$ \\
$\mathrm{P} 2-3$ & & & $6.28^{* *}$ & $8.99^{* *}$ \\
$\mathrm{P} 2-4$ & & & $4.09^{*}$ \\
\hline \multicolumn{5}{c}{ (calculated $\left.\mathrm{t}_{\mathrm{ij}} \mathrm{x} \sqrt{2}\right)$} \\
* & $\mathrm{P}<0.05 ; \mathrm{P}(0.05)=3.86, * *$ & $\mathrm{P}<0.01 ; \mathrm{P}(0.01)=4.60$
\end{tabular}

Values of teachers were not consistent across items, and especially P2-5 showed independent scoring. P2-5 intends teachers to deliver educational services to citizens and to develop their required ability. So far, social and formal education are operated by different organizations in Japan, and it would be difficult for teachers to imagine this job. Also, they felt that it was somewhat of a necessity, but they could not have an affinity with P2-5 in their routine work as other items. P2-3 also looked independent. This item demands to develop an attitude that relates to human rights of critical importance. It can be assumed that human rights are not discarded in Japan, but they are regarded as different elements from intercultural learning content.

\subsection{Principle 3}

This principle involves items regarding provision of a chance to contribute. A mean of "never thought" was increased by $27.4 \%$ in all respondents answers. However, over $70 \%$ of teachers had experiences to think cases in items, and this rate was also larger than survey rate of implementing education for international understanding shown in section 1 . Table 6 shows the geometric means of items in terms of provision of various individuals, ethnic, social, cultural, and religious groups and nations to contribute to respect, understanding, and solidarity. 
Table 6. Recognition of necessity about Principle 3

\begin{tabular}{cc}
\hline $\begin{array}{c}\text { Item } \\
\text { No. }\end{array}$ & $\begin{array}{c}\text { Geometric mean } \\
\text { (Geometric standard deviation) }\end{array}$ \\
\hline P3-1 & $3.54(2.10)$ \\
P3-2 & $2.31(2.51)$ \\
P3-3 & $2.95(2.31)$ \\
P3-4 & $3.08(2.45)$ \\
\hline
\end{tabular}

This result is depicted as a radar chart in Figure 3.

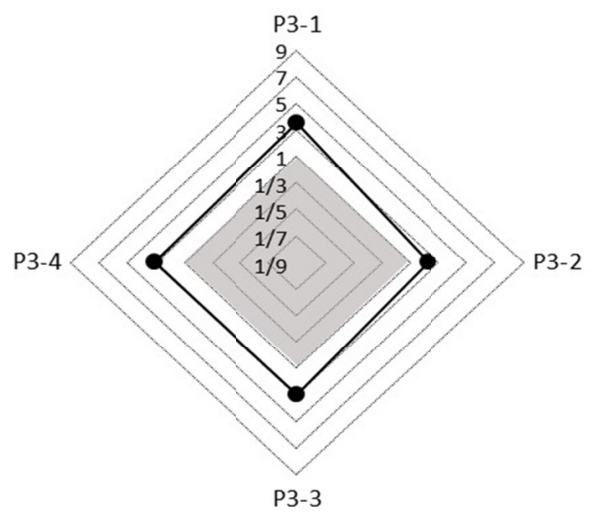

Figure 3. Result of Principle 3

In principle 3 , there were no items that were statistically significant as a necessity, but all geometric means still showed a necessary level.

P3-2 and P3-3 exhibited lower geometric means in all items of this questionnaire. It seemed that these items implied to have close communication with foreigners.

Likewise, a one-way ANOVA was introduced. Then, a significant difference was identified for items of the principle 3 $(\mathrm{F}[3,296]=2.82 ; \mathrm{P}<0.05)$.

Subsequently, we performed the multiple-comparison procedure using the Steel-Dwass test, as shown in Table 7.

Table 7. Result of the Steel-Dwass test of principle 3 items

\begin{tabular}{|c|c|c|c|}
\hline $\mathrm{i} \backslash \mathrm{j}$ & P3-2 & P3-3 & P3-4 \\
\hline P3-1 & $4.46^{* *}$ & 2.48 & 1.11 \\
\hline P3-2 & & 1.97 & 2.87 \\
\hline P3-3 & & & 1.05 \\
\hline
\end{tabular}

P3-1 implies international exchange that increases now as a special program offered by the regional educational board; and this became the highest geometric mean for this principle. On the other hand, regarding P3-2 to P3-4, it is hardly possible to find these kinds of activities in schools. Besides, P3-2 implies that a teacher needs to manage project designing, budgeting, and operation by themselves. Actually, it is difficult to find operational cost and asking permission of educational board for teachers and students to travel foreign countries, even when they felt as a necessity.

In contrast, there is little need for a teacher to travel to a foreign country in P3-1 and P3-4. When they felt that these items were more feasible, then these geometric means were slightly higher.

Although, despite the difference of content between collaboration in P3-3 and skill development in P3-4, scoring was done using a similar rating.

\section{Discussion}

When we consider the near future challenge to develop education for international understanding in Japan, there are two aspects that we should discuss from the results of this study. The first is that the history of education for international 
understanding in Japan, as noted in section 1, has been affected by the educational policy of the time and that there are many aspects of this education. This decreased teachers to critically reconsider their current content. The second is, since global view is an emerging important concept in education for international understanding in the world, the approach needs to be reformulated for Japanese teachers to move their lessons from diverging points to a global view.

\subsection{Effect on Lessons Based on Essentialism}

However, despite the positive necessity about involving multicultural content in lessons shown in P2-4, the observed necessity was lower value in P3-2 and P3-3, in which there were more deep communication with foreign people.

The most education for international understanding in Japan has planned to execute in existing school subjects (MEXT, 1996). Then, it is needed for education for international understanding to interrelate with other existing school subjects, such as social science, language, moral education, and integrated learning. Therefore, even if teachers had a global viewpoint, they could not leave the framework of school subjects.

Mabuchi (2002) strictly pointed out the cultural essentialism characteristic of Japanese people based on his experimental study (on opinions of Japanese people regarding Malaysian people). Japanese people recognized the importance of human rights and respect to minorities, but they could not have their own opinions about diversity inside Malay society. He considered that this characteristic to incorporate various inner structure into one slot had the possibility to overlook problems of equality even in our neighboring society.

In this study, teachers in Japan also greatly understood the importance of human rights and democracy, such as shown in P2-1 and P2-3. Then, as a next step, teachers need to move their conceptual positional base from a classroom to society and should have a chance to recognize the importance of multiculturalism.

As one example, MEXT investigated the situation of children of alien residents who do not enroll in schools. In the report of the sampling area, MEXT showed $0.7 \%$ of children did not enroll in schools (MEXT, 2010). In another report, children of alien residents from South American countries had increased, and it reached about 60 thousand, and about $20 \%$ of children did not enroll in schools (Matsumoto, 2008). Thus, data of social problems in Japan were extremely different from this investigation. Unfortunately, there is no comprehensive survey data to understand unregistered foreign children in Japan. Furthermore, limited people know this fact that the system of compulsory education in Japan does not reach children of foreign nationalities. Likewise, there are important cases available for intercultural education that teachers uncover or are unknown even in Japanese society.

About this matter, Ebuchi (2007) mentioned the importance of styles of intercultural education. The viewpoint of a mono-culture should integrate to the viewpoint of a comparative culture and then enhance solidarity with different cultures and lead to the viewpoint of an interactive approach, such as shown in P3-1. The deliberate promotion of teachers' recognition, especially about the social and international environment, are required to accelerate active and transformative abilities of students, such as shown in P3-4.

\subsection{Challenge for GCE in Japanese Schools}

UNESCO noted the following four pillars of intercultural education as objectives of school curricula (UNESCO, 2006).

1) Learning to know: Knowledge, Language, fundamental skills

2) Learning to do: Deal with many situations, national and international context, find a peace in society

3) Learning to live together: Joint project, learning to manage conflicts, value of pluralism, contribution

4) Learning to be: Develop personality, autonomy, judgement, responsibility

These pillars can be incorporated into three principles in this research, where principle 1 involves pillar 1 , principle 2 involves pillar 1 and 2, and principle 3 involves pillar 3 and 4. Particularly, pillar 3 and 4 are now incorporated into GCE.

Questionnaire items in this study involves three major factors of the initial stage of intercultural education. It is a necessity to have diversity education (P1-5 and P2-4), a necessity to provide education to the majority (P1-3 and P2-1), and a necessity to provide education to the minority (P1-4 and P2-2). Each factor has two different levels of education regarding pillar 1 and 2, and when we compare these corresponding pairs, the consistency of teachers' opinions in different action levels can be found. Also, the log-transformed data were processed using list-wise case deletion, and correlation coefficients were calculated. The values between P1-5 and P2-4, between P1-3 and P2-1, and between P1-4 and P2-2 were $0.524,0.462$, and 0.342 , respectively.

Then, it could be assumed that teachers showed consistent valuing in all pairs, and especially the necessity of diversity content in classroom was highly consistent. This is a promising result to introduce further enhancement of multicultural education and transformative actions that were expected to advance the intercultural education to GCE. 
The GCE pointed to the importance of raising awareness by the United Nations Secretary-General's Global Education Fist Initiative (GEFI) in 2012. UNESCO, in response to the increasing demand for support to empower learners to become responsible global citizens, has made GCE one of its key education objectives for the next eight years period since 2014 (UNESCO, 2014).

Major principles of GCE are encapsulated as follows (UNESCO, 2015b),

i) GCE stands on many foundations, with an emphasis on how they inter-connect and support each other;

ii) It includes universal principles such as human rights, democracy, inclusions, gender equality, non-discrimination, participation, empowerment, non-violence, respect for all, and so on.

iii) It is transformative and needs action at the local level and should be contextualized to help build peaceful and sustainable societies.

iv) In the perspective of lifelong learning, it begins from early childhood and continues through all levels of education into adulthood, requiring both formal and informal approaches, curricular and extracurricular interventions, and conventional and unconventional pathways to participation.

v) The focus is on the role, content, and relevance of education:

$\mathrm{v}-\mathrm{i})$ Three core conceptual and inter-related dimensions provide a framework for GCE.

v-ii) Cognitive: e.g., knowledge, understanding and critical thinking about global issues and the interconnectedness/inter-dependency of countries and different populations.

v-iii) Socio-emotional: e.g., sense of belonging to a common humanity, sharing values and responsibilities, holding rights, empathy, solidarity, and respect for differences and diversity.

v-iv) Behavioral: e.g., acting effectively and responsibly at local, national, and global levels for a more peaceful and sustainable world.

So far, human rights education and peace education are fostered in education for our national democracy, and transitions of these experiences into GCE is still needed for strong enhancement. iii) shows an idea for us to expand school activities to the local community; v-ii) shows relevance to education of multiculturalism; and v-iv) indicates contribution of schools to the globe.

Similarly, as an analytic view to leap to GCE, Uozumi (1995) depicted that education for international understanding had emphasized to recognize differences among countries and to aim at international security regarding peace, friendship, co-operation, and human rights. But, GCE asked students to include additive content to have global views and transnational actions. He explained this difference of frameworks between adjustment among sovereign nations and transnational publication.

As an example, there is a case study to introduce information of our regional minority groups into social sciences lessons in a primary school. It was possible to give a global reality of intercultural education to students by arranging content of comprehensive cases collected across Japan (Nakayama, 2005).

As another progressive example, a school that had educational programs for students from foreign countries has already introduced active implementation of international education by using an international Baccalaureate middle year program (e.g. Hoshino, 2013).

\section{Acknowledgements}

The author would like to express special thanks to in-service teachers who attended training courses in Mobara and Kimitsu sites to give us the opportunity to carry out this study.

This work was supported in part by the research project Grant-in-Aid for scientific research (B) of JSPS, project number 26301035.

\section{References}

Ebuchi, K. (2007). Introduction of research on intercultural education society of Japan. Tokyo: Tamagawa University press.

Ermenc, K. S. (2015, June 13). Educating teachers for intercultural education. Paper presented at the Annual International Conference of the Bulgarian Comparative Education Society, Sofia, Bulgaria.

Hoshino, A. (2013). Educational objectives, content, and evaluation in international Baccalaureate middle years program. Review meeting regarding ways for educational objectives, content and evaluation based on the developing capacity and competency. Retrieved from https://goo.gl/1ZVTbM 
Mabuchi, H. (2002). Discourse of intercultural understanding. Pit of the essentialism. Kyoto: Kyoto University press.

Matsumoto, A. (2008). It should use a measure of compulsory education system for Japanese dependent children who do not enroll in schools. Discovery Nikkei. Retrieved from https://goo.gl/ilsJ6I

MEXT. (1988). Measures of education and science. Retrieved from https://goo.gl/b2UHNu

MEXT. (1996). About the way of the education of our country which anticipated the 21 st century. Retrieved from https://goo.gl/DruOzX

MEXT. (2010). About the result of investigation of children of foreigners who do not enroll in schools. Retrieved from https://goo.gl/dIr381

MEXT. (2014). Result of investigation of intake of pupils and students who need support of Japanese language traiing. Retrieved from https://goo.gl/NW1wQI

MEXT. (2016). About situation of education for international understanding. Retrieved from https://goo.gl/4fF6iW

Ministry of Justice. (2016). The number of alien residents at the end of 2015. Retrieved from https://goo.gl/RnX0qr

Nakanishi, A. (1993). Theory of international education. Tokyo: Bunka Co., Ltd.

Nakayama, K. (2005). The curriculum development and practice of education for international understanding to raise awareness of "multicultural symbiosis." For comprehensive multicultural curriculum development. International understanding, (36), 207-217.

National Institute for Educational Policy Research. (2014). International comparison of situation on international education in globalization Report of JICA global plaza project. Tokyo: International Development Center of Japan.

Ootsu, K. (1994). Four approaches of global education in social sciences. Educational Studies in Japan, 61(3), 279-286.

Ootsu, K. (1997). Education for international understanding for coexistence. In S. Yoneda, K. Ootsu, I. Tabuchi, T. Hujiwara, \& Y. Tanaka (Eds.), Text book: International understanding (pp. 28). Tokyo: Kokudosha Co., Ltd.

Saaty, T. L. (1989). Group decision making and the AHP The Analytic Hierarchy Process (pp. 59-67): Springer. https://doi.org/10.1007/978-3-642-50244-6_4

Sato, G. (2007). Present and future issues in the education for international understanding. The Japanese journal of educational research, 74(2), 215-225.

Tada, T. (1997). Education for international understanding. Develop global mind. Tokyo: Touyoukan Pub.

UNESCO. (1947). Education for international understanding. Seminar workshop on education for international understanding. Retrieved from https://goo.gl/sHdGTn

UNESCO. (1954). Final report of the expert committee on education for international understanding and co-operation. Retrieved from https://goo.gl/RDdmBY

UNESCO. (1974). Recommendation concerning education for international understanding, co-operation and peace and education relating to human rights and fundamental freedoms. Report of the 18th general conference of the united nations educational, scientific and cultural organization. Retrieved from https://goo.gl/CNv5jC

UNESCO. (2006). UNESCO guidelines on intercultural education. Paris: Section of Education for Peace and Human Rights, Division for the Promotion of Quality Education, Education Sector.

UNESCO. (2014). Global citizenship education. Preparing learners for the challenges of the twenty-first century. Paris: The United Nations Educational, Scientific and Cultural Organization.

UNESCO. (2015a). Final report. Second UNESCO forum on global citizenship education: Building peaceful and sustainable societies. Paris: UNESCO.

UNESCO. (2015b). Preparing teachers for global citizenship education. Bangkok, Thailand: UNESCO.

Uozumi, T. (1995). Global education. Nagoya, Japan: Reimei Shobo Co., Ltd.

\section{Copyrights}

Copyright for this article is retained by the author(s), with first publication rights granted to the journal.

This is an open-access article distributed under the terms and conditions of the Creative Commons Attribution license which permits unrestricted use, distribution, and reproduction in any medium, provided the original work is properly cited. 